\title{
Acute toxicity test under optimal conditions of two commercial reactive dyes using the Fenton-like process: Assessment of process factors by Box- Behnken design
}

\section{Natwat Srikhao}

Khon Kaen University

Arthit Neramittagapong ( $\square$ artner@kku.ac.th )

Khon Kaen University https://orcid.org/0000-0002-7420-2196

Pongsert Sriprom

King Mongkut's Institute of Technology Ladkrabang

Sutasinee Neramittagapong

Khon Kaen University

Somnuk Theerakulpisut

Khon Kaen University

Nurak Grisdanurak

Thammasat University

\section{Research Article}

Keywords: freshwater fairy shrimps, immobilization, iron powder, commercial reactive dye, decolorization, response surface methodology

Posted Date: February 15th, 2021

DOI: https://doi.org/10.21203/rs.3.rs-164955/v1

License: (c) (i) This work is licensed under a Creative Commons Attribution 4.0 International License. Read Full License 
1

2

3

4

5

Acute toxicity test under optimal conditions of two commercial reactive dyes using the Fenton-like process:

(1)

4

(

(

7

8

(1)

10

\footnotetext{
${ }^{4}$ Energy Management and Conservation Office, Faculty of Engineering, Khon Kaen University, Khon Kaen, 40002,
}

(1)

Thailand

${ }^{5}$ Department of Chemical Engineering, Faculty of Engineering, Thammasat University, Pathumthani, 12000, Thailand 


\begin{abstract}
Reactive dye has generally been used in woven cotton fabric dyeing industries. Some treatments of several reactive dyes may produce more toxicity than the original dyes. The objectives of this study were to find the optimal condition on dye degradation efficiency of commercial reactive red dye 36 (DR36) and reactive violet dye 30 (DV30) using Fenton-like reaction, and to determine acute toxicity by static bioassay method under the optimal condition. The experiment was designed by Box Behnken Design (BBD), in which an initial $\mathrm{pH}$, catalyst dosage and initial concentration of $\mathrm{H}_{2} \mathrm{O}_{2}$ were considered as independent variables. The results showed that only an initial pH solution was the principal parameter which influenced decolorization of the reactive dyes. Other factors were much less

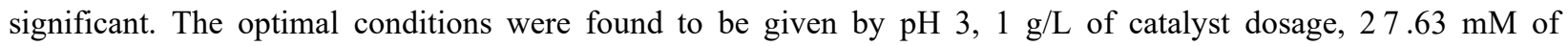
concentration of $\mathrm{H}_{2} \mathrm{O}_{2}$ for DR36, and $\mathrm{pH} 3,1.35 \mathrm{~g} / \mathrm{L}$ of catalyst dosage, $45 \mathrm{mM}$ of concentration of $\mathrm{H}_{2} \mathrm{O}_{2}$ for DV30. Ninety percent of both decolorization were achieved in $30 \mathrm{~min}$. Acute toxicity tests of the treated solutions using freshwater fairy shrimps (Streptocephalus sirindhornae) revealed that the shrimps survived longer than $24 \mathrm{~h}$, indicating that the treated solutions were not acutely toxic. The average leaked iron, ADMI value and total organic carbon were found to be less than $10 \mathrm{ppm}, 5 \mathrm{ADMI}$ and $9.17 \mathrm{ppm}$ respectively, in the treated samples. This research demonstrated an efficient method for decolorization of the reactive dyes with low acute toxicity.
\end{abstract}

Keywords: freshwater fairy shrimps, immobilization, iron powder, commercial reactive dye, decolorization, response surface methodology

*Corresponding author E-mail: artner@kku.ac.th (Arthit Neramittagapong) 
70

71

72

73

74

75

76

77

78

79

80

81

82

83

84

85

86

87

88

89

90

91

92

93

94

95

96

\section{Introduction}

Global textile industries have grown unstoppably for several decades, more over 700,000 ton of about 10,000

types of dyes and pigments were annually produced (Lyu et al. 2016; Holkar et al. 2016). Consequently, dye, especially reactive dye, has become an important feedstock used in the industry. Since dye cannot be consumed totally in the dyeing process, the unreacted dye could remain in the wastewater discharge, causing the wastewater to have unpleasant appearance and toxicity. In Thailand it has been regulated that wastewater discharge should contain dye concentration less than $300 \mathrm{ppm}$ (Nidheesh et al. 2018) and/or the color of the wastewater should be less than 300

ADMI unit. Some reactive dyes were also declared as high toxins promoting carcinogenesis and mutagenesis (Nasuha et al. 2016; Mahmood Reza Sohrabi et al. 2016).

To meet all the requirements of wastewater, several techniques have been used to reduce dye concentration before the wastewater can be discharged. Advanced oxidation processes (AOP) are some promising methods used for the purpose. These processes have been classified as photo-catalytic (Ayyob et al. 2020), ozonation (Powar et al. 2020), and Fenton reaction (Ertugay \& Acar 2017). Among the AOPs, the Fenton reaction can extensively be used to decompose hard biodegradable organics, including different dyes (Nasuha et al. 2016; Youssef et al. 2016), and textile discharge (Ghanbari et al. 2014; Punzi et al. 2015). The reaction involves a reaction of ferrous ion with $\mathrm{H}_{2} \mathrm{O}_{2}$ to produce $\mathrm{OH}^{*}$ free radicals having extremely strong oxidation capacity, especially in narrow pH range of 2.8-3.0 (Ghanbari et al. 2014; Glugoski et al. 2017). The narrow pH range makes the Fenton reaction difficult to implment (Wang et al. 2017). The heterogeneous Fenton-like catalytic technique has therefore been used more widely, as has been reported on laterite soil (Khataee et al. 2015), red mud (Dias et al. 2016), montmorillonite clay (Fida et al. 2017), zeolite (Rache et al. 2014) and zero valent iron nanoparticles (Vilardi et al. 2018).

Reactive dye such as DR36 and DV30 possesses prominent properties for their stabilities (Malade \& Deshannavar 2018) and high level of washing fastness (Nallathambi \& Venkateshwarapuram Rengaswami 2017). Nasuha et al. (2016) have studied decolorization of reactive black 5 using Fenton-like. Initial dye concentration, hydrogen peroxide concentration, initial $\mathrm{pH}$ of a solution and amount of initial catalyst were selected as the main factors for studying this reaction. Khataee et al. (2016) have also studied the effects of operating parameters of the reaction such as catalyst dosages, $[\mathrm{pH}],\left[\mathrm{H}_{2} \mathrm{O}_{2}\right]$ on their decolorization of Reactive Orange 29 dye. However, the 
97 decolorization of these reactive dyes have been studied by considering one factor at a time (OFAT). Interaction effects

98 of the parameters were not studied during the tests.

99 Statistical experimental design could be a better approach in multi-factor study. A systematic study using 100 response surface methodology (RSM), like central composite design (CCD) and Box Behnken Design (BBD), could 101 be used to set up and analyze the experimental data. Some of the advantages of the RMS include its ability to explain 102 both individual and interaction effects, and optimizing decolorization condition. In addition, it's has successfully been 103 applied to various oxidation processes to optimize the experimental design condition (Fu et al. 2009; Berkani et al. 104 2020).

In this study, the decolorization of DR36 and DV40 dye was implemented by BBD under three factors 106 simultaneously, including $\mathrm{pH}$, catalyst loading, and amount of $\mathrm{H}_{2} \mathrm{O}_{2}$. The study was carried out using iron powder in

107 a Fenton-like reaction. The experiment was set up in a range of $\mathrm{pH}$ 3-7, Catalyst 0.01-1.5 g/L, and $\mathrm{H}_{2} \mathrm{O}_{2}$ 0.5-100 mM.

108 The optimum condition and the most influential factor(s) in decolorization of the reactive dyes were the objective of 109 this study. The water after the treatment was also tested for acute toxicity by using fairy shrimps (Streptocephalus 110 sirindhornae).

111

112 2.Materials and methods

$113 \quad 2.1$ Materials

Reactive red dye 36 (DR36) and violet dye 30 (DV30) (without heavy metal, Dylon, England) used in this 115 study were purchased in Thailand. The Fenton-like experiment were carried out using commercial iron-powder grade 116 (99.64\% Gammaco, Thailand). $\mathrm{H}_{2} \mathrm{O}_{2} 30 \%$ (QRëC, New Zealand). NaOH (98\%wt Ajax Finechem Pty Ltd, Auckland, 117 New Zealand) and $\mathrm{H}_{2} \mathrm{SO}_{4}$ (96\%wt RCI Labscan Limited, Thailand) were used to adjust the solution $\mathrm{pH}$ to the desired 118 levels. Ethanol (99.8\% Analar NORMAPUR ${ }^{\circledR}$ ACS, Reag.Ph.Eur., France) was used to wash the catalyst. Nylon 119 filter membrane (Syring filter 0.45 Micron CNW, China) was used to filter the sample solution before determining 120 the color values using UV-Vis spectrophotometer (SPECORD,Analytik Jena, Germany). All solutions were prepared 121 with deionized water (DI water).

122

123 2.2 Experimental 
Iron-powder was sieved to the size range of 100-500 mesh. It was washed by Deionized water and ethanol, and then dried at $80^{\circ} \mathrm{C}$ for 1 hour. The obtained material was immediately used right after the preparation. BoxBehnken design (Software Minitab 16) was used to randomize the experimental values of the three factors at three

127 levels as shown in Table 1. The studied factors included initial pH, catalyst dosage, and initial concentration of $\mathrm{H}_{2} \mathrm{O}_{2}$.

128 The experiments were performed in a batch-wise system of $600 \mathrm{~mL}$ container, under room temperature. The decolorization of reactive dye (300 ppm) was carried out using different initial concentrations of $\mathrm{H}_{2} \mathrm{O}_{2}(0.5-100 \mathrm{mM})$, the catalyst dosage (0.01-1.5 g/L) and $\mathrm{pH}$ (3-7). One molar of $\mathrm{H}_{2} \mathrm{SO}_{4}$ or $\mathrm{NaOH}$ solution was used to adjust the solution $131 \mathrm{pH}$.

During the test, the remaining concentration of the reactive dye in the solution was withdrawn 30 minutes after the beginning of the experiment, and analyzed for the percentage of decolorization efficiency (DE\%) and the

134 American Dye Manufacturers Institute (ADMI) value by UV-Vis spectrophotometer. The Non-Purgeable Organic Carbon (NPOC) method was used to determine the TOC value. These values were compared with those of the solution withdrawn prior to the commencement of the experiment.

The catalyst was further characterized for its surface area and composition by $\mathrm{N}_{2}$ Adsorption-Desorption (ASAP 2010, Micromeritics, USA) and X-Ray Fluorescence Spectrometry (SEA1000A, Seiko Instruments GmbH, Germany), respectively. After 30 minutes of reaction, the solution was analyzed for iron leachate by Inductively Coupled Plasma-Optical Emission Spectrometer (Optima 8x00 Series, PerkinElmer, United States of America).

$\underline{\text { Table } 1 \text { Box-Behnken design for varying the factors }}$

\begin{tabular}{|c|c|c|c|c|}
\hline \multirow{2}{*}{ Factors } & \multirow{2}{*}{ Symbol } & \multicolumn{3}{|c|}{ Levels of factors } \\
\hline & & -1 & 0 & 1 \\
\hline Initial pH & $\left(\mathrm{X}_{1}\right)$ & 3 & 5 & 7 \\
\hline Catalyst dosage $(\mathrm{g} / \mathrm{L})$ & $\left(\mathrm{X}_{2}\right)$ & 0.01 & 0.755 & 1.5 \\
\hline Initial concentration of $\mathrm{H}_{2} \mathrm{O}_{2}(\mathrm{mM})$ & $\left(\mathrm{X}_{3}\right)$ & 0.5 & 50.25 & 100 \\
\hline
\end{tabular}
technique as follows:

$$
Y=\beta_{0}+\beta_{1} X_{1}+\beta_{2} X_{2}+\beta_{3} X_{3}+\beta_{4} X_{1}^{2}+\beta_{5} X_{2}^{2}+\beta_{6} X_{3}^{2}+\beta_{7} X_{1} X_{2}+\beta_{8} X_{1} X_{3}+\beta_{9} X_{2} X_{3} \pm \varepsilon
$$

147 In which $\mathrm{Y}$ is dye removal efficiency (response function), $\beta_{\mathrm{i}}$ are regression coefficient, $\mathrm{X}_{\mathrm{i}}$ are independent 148 variables, and $\varepsilon$ is value of the error. 
149

150

151

152

153

154

155

156

157

158

159

160

161

162

163

164

165

166

167

168

169

170

171

172

173

174

175

176

177

2.3 Acute toxicity assays

Young freshwater fairy shrimps (Streptocephalus sirindhornae Sanoamuang) were obtained from a stock maintained at the Department of Fisheries, Khon Kaen University. The acute toxicity and immobilization tests were performed according to 202 of OECD Guidelines for Testing of Chemicals (OCDE, 1984) with modifications. For the tests, 20 of neonates were divided into five groups of four animals each. The first and second groups were exposed to both (DR36 andDV30) of the original dye diffusion $(300 \mathrm{mg} / \mathrm{L})$, the third and fourth groups in the treated water from the optimal condition in Fenton-like process (DR36 and DV30), and the final group in the water obtained from the source of fairy shrimps (control water).

The water obtained from the source of fairy shrimp culture was used as the control water. The acute toxicity assays can be assessed by counting the number of dead and surviving neonates at $0.5,1,6,12,24,36,48,60$ hours and compared with the control water. Prior to the test, the solution of every experimental batch was adjusted to the $\mathrm{pH}$ value of 7.66 before adding the neonates except the control water. This experiment did not have any light control. Therefore, the daytime was assumed to be approximately $12 \mathrm{~h}$, and $12 \mathrm{~h}$ nighttime.

3.Results and discussion

3.1 Characteristics of catalysts

The specific surface area was determined to be $3.932 \mathrm{~m}^{2} / \mathrm{g}$ by the Brunauer-Emmett-Teller (BET) method using the $\mathrm{N}_{2}$ Adsorption-Desorption Semisorb, (ASAP 2010, Micromeritics, USA). The purity of the iron-powder was found to be $99.64 \%$ wt using X-Ray Fluorescence Spectrometry.

\subsection{Dye degradation}

The values of dependent and independent factors, and the condition for every experimental data set which was obtained from Box-Behnken design (Table 1) are presented in Table 2. The decolorization efficiency (DE\%) of DR36 and DV30 were calculated by Equation 2 and shown in Table 2.

$$
D E \%=\frac{C_{0}-C_{t}}{C_{0}} \times 100
$$

where $\mathrm{DE} \%$ is the decolorization efficiency, $\mathrm{C}_{0}$ is the initial concentration of the dye, and $\mathrm{C}_{\mathrm{t}}$ is concentration of the dye at $30 \mathrm{~min}$. 
178 179 180

\begin{tabular}{|c|c|c|c|c|c|}
\hline Run & Initial $\mathrm{pH}$ & Catalyst dosage (g/L) & $\mathrm{H}_{2} \mathrm{O}_{2}(\mathrm{mM})$ & $\begin{array}{c}\% \text { DE of } \\
\text { DR36 dye } \\
30 \mathrm{~min} \\
\end{array}$ & $\begin{array}{c}\% / \mathrm{DE} \text { of DV30 } \\
\text { dye } \\
30 \mathrm{~min} \\
\end{array}$ \\
\hline 1 & 5 & 0.01 & 0.5 & 19.523 & 24.945 \\
\hline 2 & 3 & 0.01 & 50.25 & 42.668 & 78.061 \\
\hline 3 & 7 & 0.01 & 50.25 & 7.768 & 10.950 \\
\hline 4 & 3 & 0.755 & 0.5 & 99.244 & 94.770 \\
\hline 5 & 5 & 0.01 & 100 & 19.994 & 22.047 \\
\hline 6 & 7 & 0.755 & 0.5 & 21.411 & 10.833 \\
\hline 7 & 5 & 1.5 & 0.5 & 39.764 & 64.757 \\
\hline 8 & 7 & 1.5 & 50.25 & 22.460 & 25.771 \\
\hline 9 & 3 & 1.5 & 50.25 & 94.033 & 77.113 \\
\hline 10 & 7 & 0.755 & 100 & 19.144 & 4.785 \\
\hline 11 & 5 & 1.5 & 100 & 45.714 & 93.609 \\
\hline 12 & 5 & 0.755 & 50.25 & 62.514 & 64.182 \\
\hline 13 & 5 & 0.755 & 50.25 & 62.796 & 81.096 \\
\hline 14 & 5 & 0.755 & 50.25 & 53.157 & 64.208 \\
\hline 15 & 3 & 0.755 & 100 & 92.751 & 62.056 \\
\hline
\end{tabular}

181

Table 2 Results of the Box-Behnken experimental design for dye decolorization efficiency (DE\%) of DR36 and DV30.

The coefficients of the response functions for various independent variables were obtained by correlating the experimental results with the response functions by using a Minitab 16 statistical software. The response functions for DR36 and DV30 were obtained by the Least Square of Error method as Equations 3 and 4, respectively for predicting the dye decolorization efficiency.

$\% Y(D R 36)=55.43-30.25 X_{1}+9.70 X_{2}-3.9 X_{3}-1.62 X_{1}^{2}-20.06 X_{2}^{2}-7.01 X_{3}^{2}-8.21 X_{1} X_{2}+3.34 X_{1} X_{3}+$ $1.76 X_{2} X_{3}$

$$
\% Y(D R 36)=69.83-32.46 X_{1}+15.66 X_{2}-1.6 X_{3}-15.04 X_{1}^{2}-6.81 X_{2}^{2}-11.68 X_{3}^{2}+3.94 X_{1} X_{2}+6.67 X_{1} X_{3}+
$$
$7.94 X_{2} X_{3}$ 
Figure 1 and 2 can be used to verify the accuracy of Equations 3 and 4, respectively. Figures 1a and 2a indicate that the data were distributed on straight lines independently. Figure 1B and $2 \mathrm{~B}$ show the stability of variance to be dispersed around the zero. The histogram of the Figure $1 \mathrm{C}$ and $2 \mathrm{C}$ demonstrate that the standard deviation of the data was well distributed (bell-shape) and tend to the center. Lastly, Figure 1D and 2D show the standardized residual of the data with respect to the observation order. These two figures reveal that the order of the experiment was well distributed, indicating that the experimental design was well randomized.
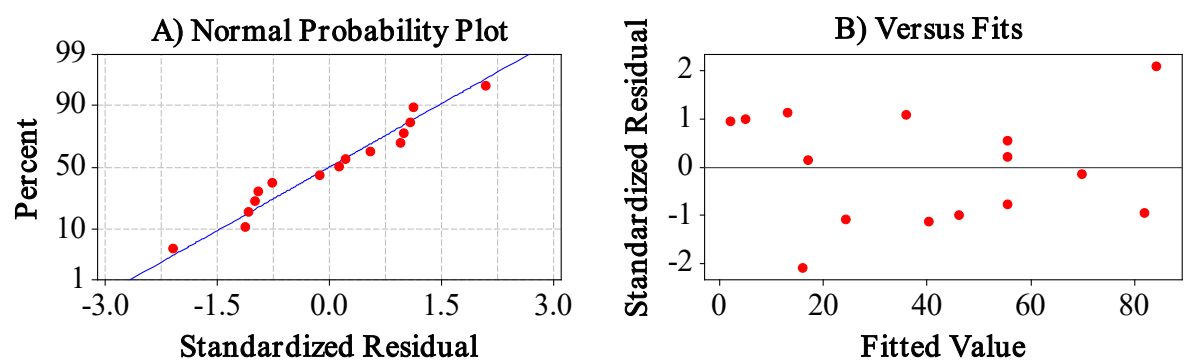

C) Histogram
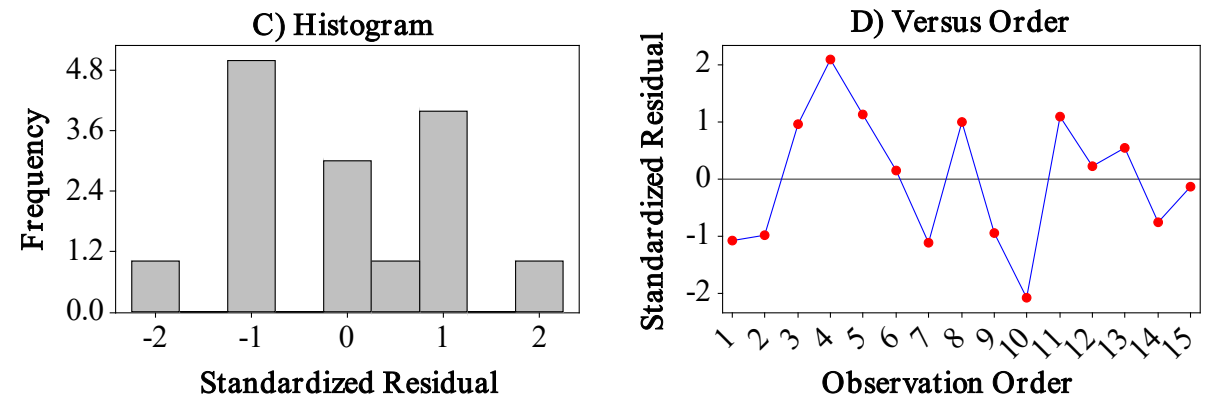

Fig. 1 Standard error compared to a) standardized residual b) versus fits c) Histogram d)Versus order. 


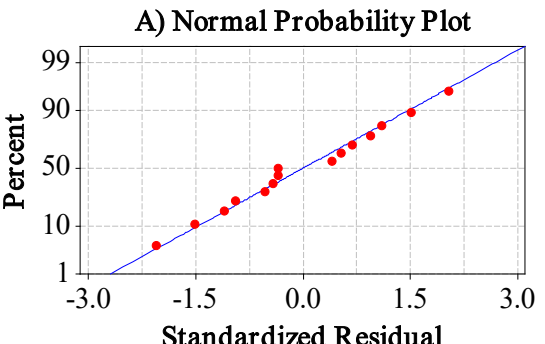

C) Histogram

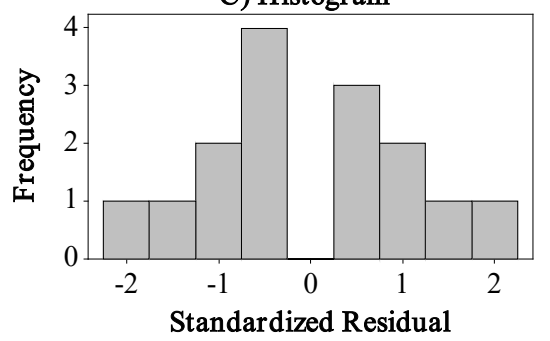

For DV30.

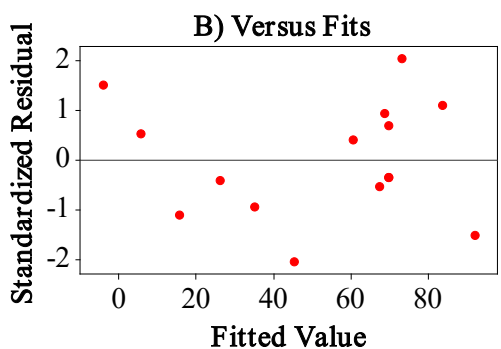

D) Versus Order

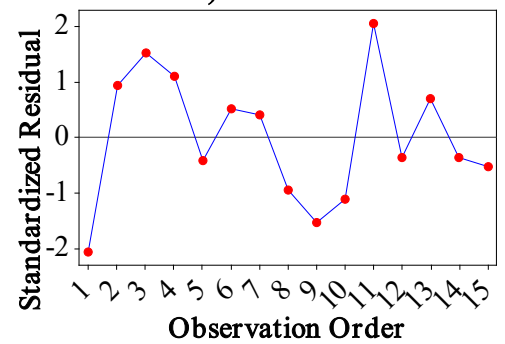

Fig. 2 Standard error compared to A) standardized residual B) versus fits C) Histogram D) Versus Order.

Based on the statistical data of Figures 1 and 2, it can be seen that the data obtained were well distributed and independent. In other words, no abnormal statistical data were observed. Therefore, Equations 3 and 4 can be used with some degree of confidence. Equations 3 and 4 were also analysed for variance by ANOVA test with $95 \%$ confidence interval. The $\mathrm{F}_{\text {value }}$ and $\mathrm{P}_{\text {value }}$ were considered for each variable presented in Table 3.

From Table 3, it should be noted that only terms of linear source, which have statistically significant effects on the DE\% of DR36 and DV30. For DR36, the significant factors were found to be initial $\mathrm{pH}\left(\mathrm{X}_{1}\right)$, the catalyst dosage $\left(\mathrm{X}_{2}\right)$ and the term of $\mathrm{X}_{2}^{2}$. Even though the initial concentration of hydrogen peroxide $\left(\mathrm{X}_{3}\right)$ was not significant, it is necessary for a Fenton-like reaction as the reducing agent. For DV30, it was found that only the initial $\mathrm{pH}$ was the significant factor, while other factors were insignificant, but they were needed for the reaction.

However, the applicability of Equations 3 and 4 must be judged by the term of Lace of fit which is used to indicate to the error of these equations. Table 3 shows that the Lace of fit values for DR36 and DV30 were not significant. Therefore, the equations are statistically reliable without a need to remove any factors from the equations (Ay et al. 2009), indicating the model can be used to forecast the DE\%. 
Table 3 ANOVA test for response function Y (DE\%)

\begin{tabular}{|c|c|c|c|c|c|c|c|}
\hline \multirow{2}{*}{ Source } & \multirow{2}{*}{$\mathrm{DF}$} & \multicolumn{3}{|c|}{ DR36 } & \multicolumn{3}{|c|}{ DV30 } \\
\hline & & F-value & P-value & Result & F-value & P-value & Result \\
\hline Regression & 9 & 10.71 & 0.009 & Significant & 3.46 & 0.093 & Insignificant \\
\hline Linear & 3 & 26.03 & 0.002 & Significant & 8.82 & 0.019 & Significant \\
\hline $\mathrm{X}_{1}$ & 1 & 69.76 & 0.000 & Significant & 21.42 & 0.006 & Significant \\
\hline $\mathrm{X}_{2}$ & 1 & 7.18 & 0.044 & Significant & 4.98 & 0.076 & Insignificant \\
\hline $\mathrm{X}_{3}$ & 1 & 1.16 & 0.331 & Insignificant & 0.05 & 0.828 & Insignificant \\
\hline Square & 3 & 5.07 & 0.056 & Insignificant & 1.13 & 0.420 & Insignificant \\
\hline $\mathrm{X}_{1}^{2}$ & 1 & 0.09 & 0.774 & Insignificant & 2.12 & 0.205 & Insignificant \\
\hline $\mathrm{X}_{2}^{2}$ & 1 & 14.15 & 0.013 & Significant & 0.44 & 0.538 & Insignificant \\
\hline $\mathrm{X}_{3}^{2}$ & 1 & 1.73 & 0.246 & Insignificant & 1.28 & 0.309 & Insignificant \\
\hline Interaction & 3 & 1.03 & 0.453 & Insignificant & 0.42 & 0.749 & Insignificant \\
\hline $\mathrm{X}_{1} \times \mathrm{X}_{2}$ & 1 & 2.57 & 0.170 & Insignificant & 0.16 & 0.707 & Insignificant \\
\hline $\mathrm{X}_{1} \times \mathrm{X}_{3}$ & 1 & 0.42 & 0.543 & Insignificant & 0.45 & 0.531 & Insignificant \\
\hline $\mathrm{X}_{2} \times \mathrm{X}_{3}$ & 1 & 0.11 & 0.751 & Insignificant & 0.64 & 0.460 & Insignificant \\
\hline $\begin{array}{c}\text { Residual } \\
\text { Error }\end{array}$ & 5 & & & & & & \\
\hline Lace-of-fit & 3 & 4.71 & 0.180 & Insignificant & 6.22 & 0.142 & Insignificant \\
\hline Pure-Error & 2 & & & & & & \\
\hline Total & 14 & & & & & & \\
\hline \multicolumn{8}{|c|}{ F-test $95 \%$ confidence $(\alpha=0.05)$} \\
\hline \multicolumn{2}{|l|}{ Source } & \multicolumn{2}{|c|}{ DF 1} & \multicolumn{2}{|c|}{ DF 2} & \multicolumn{2}{|r|}{$F$ critical } \\
\hline \multicolumn{2}{|c|}{$\mathrm{F}_{(0.05, \mathrm{DF} 1, \mathrm{DF} 2)}$} & \multicolumn{2}{|r|}{9} & \multicolumn{2}{|c|}{5} & \multicolumn{2}{|r|}{4.77} \\
\hline \multicolumn{2}{|c|}{$\mathrm{F}_{(0.05, \mathrm{DF} 1, \mathrm{DF} 2)}$} & \multicolumn{2}{|r|}{3} & \multicolumn{2}{|c|}{5} & \multicolumn{2}{|r|}{5.41} \\
\hline \multicolumn{2}{|c|}{$\mathrm{F}_{(0.05, \mathrm{DF} 1, \mathrm{DF} 2)}$} & \multicolumn{2}{|r|}{1} & \multicolumn{2}{|c|}{5} & \multicolumn{2}{|r|}{6.61} \\
\hline \multicolumn{2}{|c|}{$\mathrm{F}_{(0.05, \mathrm{DF} 1, \mathrm{DF} 2)}$} & \multicolumn{2}{|r|}{3} & \multicolumn{2}{|c|}{2} & \multicolumn{2}{|r|}{19.16} \\
\hline
\end{tabular}

267 against the experimental values as shown in Fig.3A and 3B for DR36 and DV30, respectively. As shown in Fig. 3A,

268 the equation obtained fits approximately well with experimental results (less than 10\% error). Similarly, Fig 3B reveals

269 similar results but with less accuracy (less than $15 \%$ error). It should be noted, however, for the range of $70-80 \%$ of

270 decolorization the model for DV30 can be used to predict decolorization with improved accuracy (less than $10 \%$

271 error). Consequently, it can be concluded that both of the models were in reasonably good agreement with the 272 experiment. 
276

277

278

279

280

281

282

283

284

285

286

287

288

289

290

291

292

293

294

295

296

297

298

299

300

301

302

303

304

305

306

307

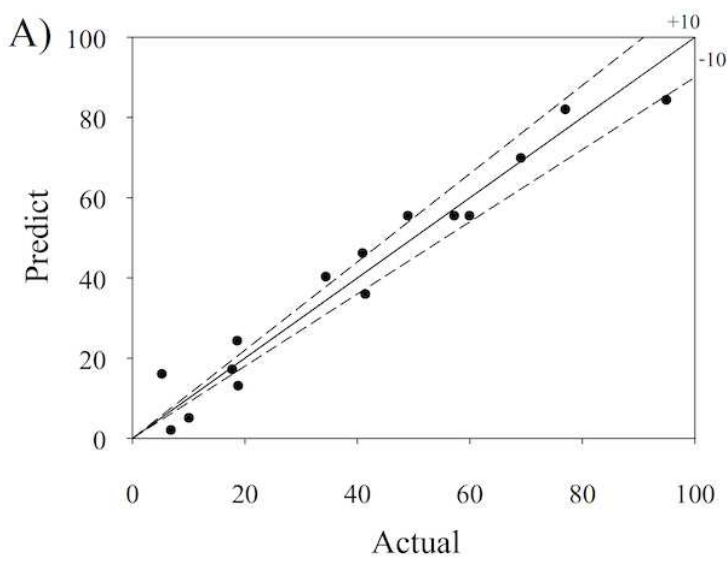

Fig. 3. Experimental and predicted equation results for decolorization A) DR36 B) DV30

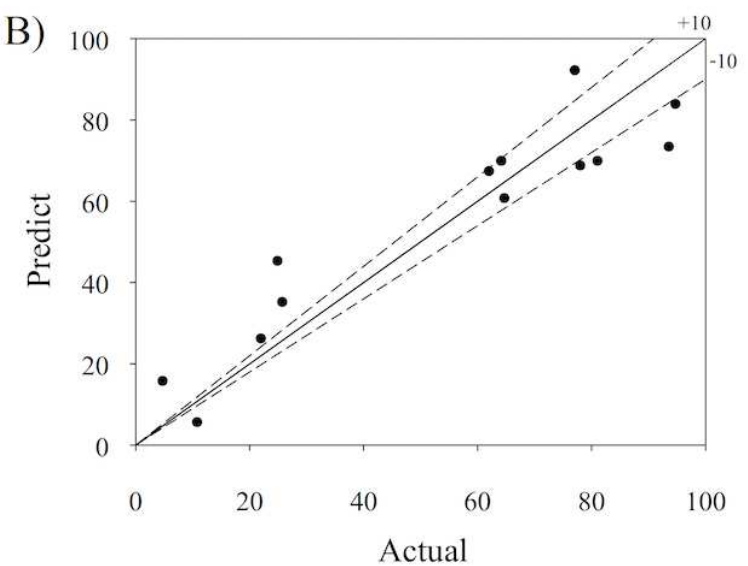

\subsection{Effects of parameters on decolorization efficiency}

The initial $\mathrm{pH}\left(\mathrm{X}_{1}\right)$ was found to be the most influential factor on the decolorization efficiency. The F-value can confirm this in Table 3 where the $F_{\text {value }}$ values were found to be 69.76 and 21.42 for DR36 and DV30, respectively.

On the contrary, the catalyst dosage $\left(\mathrm{X}_{2}\right)$ and the initial concentration of $\mathrm{H}_{2} \mathrm{O}_{2}\left(\mathrm{X}_{3}\right)$ were much less influential on decolorization.

More interestingly, based on statistical results in Table 3, it should be noted that the interaction effects between the insignificant variables and significant variables were not significant. However, the interaction effects of the variables were shown to influence decolorization by response surface methodology (Fig.4).

The interaction effects of between $\left(\mathrm{X}_{1}\right)$ and $\left(\mathrm{X}_{2}\right)$ were depicted in Fig. 4A and Fig.4D, whereas Fig. 4B and Fig. 4E show the interaction effects between $\left(\mathrm{X}_{1}\right)$ and $\left(\mathrm{X}_{3}\right)$. It is seen that \%DE increases with the catalyst dosage and $\mathrm{H}_{2} \mathrm{O}_{2}$ at a constant $\mathrm{pH}$ of 3 . At other $\mathrm{pH}$ values, the $\% \mathrm{DE}$ is slightly affected by the catalyst dosage and initial concentration of $\mathrm{H}_{2} \mathrm{O}_{2}$. At the initial $\mathrm{pH}$ of 3, the decolorization efficiency is the highest. This finding was also observed by Khataee et al. (2015), who used the iron-rich laterite soil as the catalyst. This can be explained by the instability of $\mathrm{H}_{2} \mathrm{O}_{2}$ and depressed oxidation potential of hydroxyl radicals at higher $\mathrm{pH}$ (Fida et al., 2017). In addition, the alkaline solution causes the Ferrous ion $\left(\mathrm{Fe}^{2+}\right)$ to transform to be Iron (II) hydroxide $\left(\mathrm{Fe}(\mathrm{OH})_{2}\right)$ according to Equation 5. Fe in this form is inactive (Ertugay \& Acar 2017; Chu et al. 2012). 
Fig. 4C and Fig. 4F show the DE\% tends to the maximum value as $\mathrm{X}_{2}$ and $\mathrm{X}_{3}$ increase until some limits. The limits of $\mathrm{X}_{2}$ were found to be $1.3 \mathrm{~g} / 1$ for DR36 and $1.5 \mathrm{~g} / 1$ for DV30. The limits were due to excessive active sites of the catalyst, resulting in excessive ferrous ions (Khataee et al., 2015; Fida et al., 2017). In theory, the ferrous ion can react with $\mathrm{H}_{2} \mathrm{O}_{2}$ to produce more hydroxyl radicals (Khataee et al. 2015; Ma et al. 2015), but excessive ferrous ions will result in some of the ions becoming the scavengers of the hydroxyl radicals (Li et al. 2017; Bouzayani et al. 2017) as illustrated in Equations 6-8.

$$
\mathrm{X}_{-} \mathrm{Fe}^{2+}+\mathrm{H}_{2} \mathrm{O}_{2} \rightarrow \mathrm{X}_{-} \mathrm{Fe}^{3+}+\mathrm{H}_{2} \mathrm{O}+\mathrm{OH}^{\circ}
$$

$$
\mathrm{X}_{-} \mathrm{Fe}^{2+}+\mathrm{HO}^{\circ} \rightarrow \mathrm{X}_{-} \mathrm{Fe}^{3+}+\mathrm{HO}^{-}
$$

$$
\mathrm{X}_{-} \mathrm{Fe}^{3+}+\mathrm{H}_{2} \mathrm{O}_{2} \rightarrow \mathrm{X}_{-} \mathrm{Fe}^{2+}+\mathrm{H}^{+}+\mathrm{HOO}^{\circ}
$$

where $\mathrm{X}$ is the solid catalyst support.

$$
\text { In a similar manner to the catalyst dosage, the } \mathrm{DE} \% \text { increases with } \mathrm{H}_{2} \mathrm{O}_{2} \text { concentration until some limits. The }
$$
$\mathrm{H}_{2} \mathrm{O}_{2}$ concentration over $60 \mathrm{mM}$ tends to decrease the $\mathrm{DE} \%$. Excessive $\mathrm{H}_{2} \mathrm{O}_{2}$ will result in hydroxyl radical scavenging (Mahmood R. Sohrabi et al., 2017; Quadrado \& Fajardo, 2017; Grisales et al., 2019) according to Equations 9 and 10.

$$
\begin{aligned}
& \mathrm{H}_{2} \mathrm{O}_{2}+\mathrm{OH}^{\circ} \rightarrow \mathrm{H}_{2} \mathrm{O}+\mathrm{HOO}^{\circ} \\
& \mathrm{HOO}^{\circ}+\mathrm{OH}^{\circ} \rightarrow \mathrm{H}_{2} \mathrm{O}+\mathrm{O}_{2}
\end{aligned}
$$

$$
\text { In conclusion, the study of the effects of the parameters on decolorization efficiency, as presented in Figure 4, }
$$
reveals that the most influential parameter is the initial $\mathrm{pH}$, which should be controlled at $\mathrm{pH} 3$ for the best dye decolorization efficiency. The other factors, namely catalyst dosage and concentration of $\mathrm{H}_{2} \mathrm{O}_{2}$, should respectively be kept in the ranges of 0.9-1.2 g/L, and 20-35 mM of $\left[\mathrm{H}_{2} \mathrm{O}_{2}\right]$ for DR36, and 1.3-1.5 g/L, and 40-50 $\mathrm{mM}^{-}$of $\left[\mathrm{H}_{2} \mathrm{O}_{2}\right]$ for DV30. 


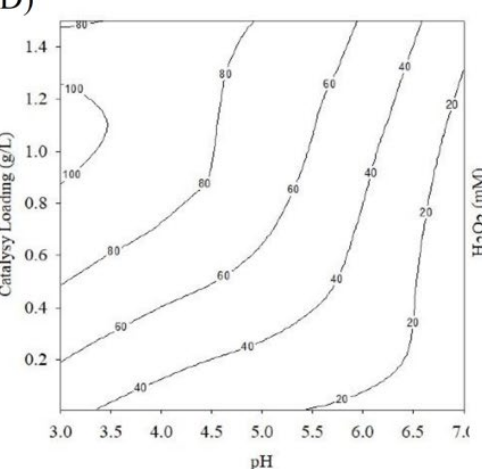

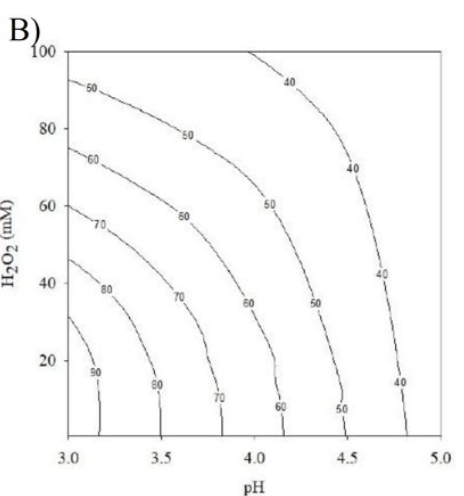
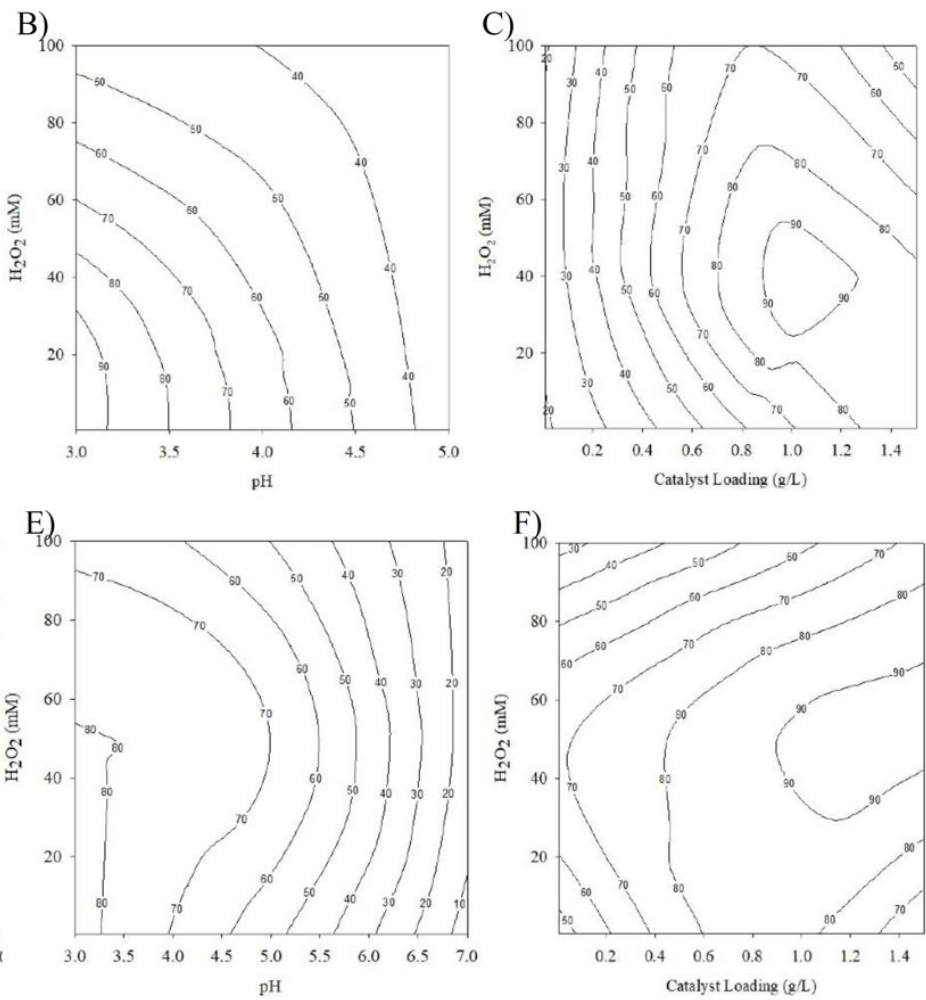

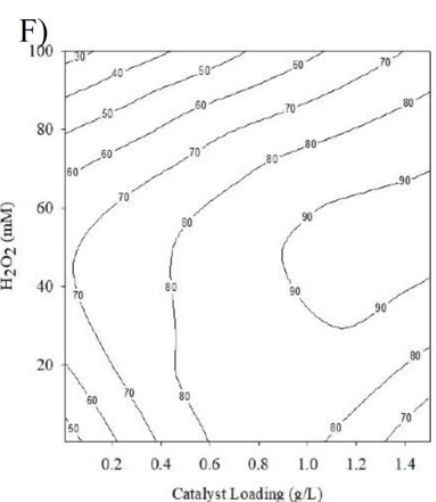

Fig. 4 Contour plot illustrations, the interaction effect of variables on dye decolorization efficiency in the Fenton -like process in white (A-C) For DR36 and (D-F) for DV30.

\subsection{Optimal condition and asseveration of the findings}

The optimal conditions of dyes were predicted by using Equations 3 and 4 for DR36 and DV30, respectively.

These equations were obtained by the Least Square method based on the numerical values generated from the experimental data by Minitab 16 software. The optimal conditions were found to be $\mathrm{pH} 3,1 \mathrm{~g} / \mathrm{L}$ of catalyst dosage, $27.63 \mathrm{mM}$ of $\mathrm{H}_{2} \mathrm{O}_{2}$ For DR36, and $\mathrm{pH} 3,1.35 \mathrm{~g} / \mathrm{L}$ of catalyst dosage, $45 \mathrm{mM}^{\circ} \mathrm{H}_{2} \mathrm{O}_{2}$ for DV30. Under these predicted conditions, the best of DE\% were found to be $89.38 \%$ and $92.33 \%$ for DR36 and DV30, respectively. and $92.97 \%$ with a standard deviation of $8.88 \%$ for DR36 and DV30, respectively. The experimental results were, therefore, comparable with the predicted values with the standard deviations as described. 
Furthermore, under these optimal conditions, the average values of leached iron, TOC, and ADMI unit were also determined. These results were less than $10 \mathrm{ppm}, 9.17 \mathrm{ppm}, 5$ ADMI, respectively. The treated water was therefore in compliance with American Dye Manufacturing Institute, and Thailand's Industrial Discharge Water standards.

3.5 Acute toxicity

Fig. 5 shows the results of acute toxicity test of the treated water with the optimal condition. The test was performed by counting fatalities of the fairy shrimps exposed to the treated water and the original untreated water. The result showed, after 24 hours, that no deaths were observed in all of the batches. This leads to the conclusion that there was no difference in acute toxicity of the treated and untreated water.

However, when the toxicity test reached $48 \mathrm{~h}$, only $25 \%$ of the neonates in the original, untreated water with DR36 died, whereas the fatalities in the case of DV30 were $27 \%$. In the case of treated waters and cultured water were found not any death. At $60 \mathrm{~h}$, the treated water showed a slightly better survival rate than the original, untreated water. The survival rate was found to be $76 \%$ for treated waters (both DR36 and DV30), while the original, untreated water showed $74 \%$ and $72 \%$ for DR36 and DV30, respectively. No fatality was observed in the control water.

In conclusion, only a slight difference in toxicity between the treated and untreated water. Fernandesa et al. (2018). also observed a similar result in their acute toxicity test $(24 \mathrm{~h})$. Therefore, the Fenton-like reaction under the optimal condition could be well applied to treat wastewater from the dyeing industry.

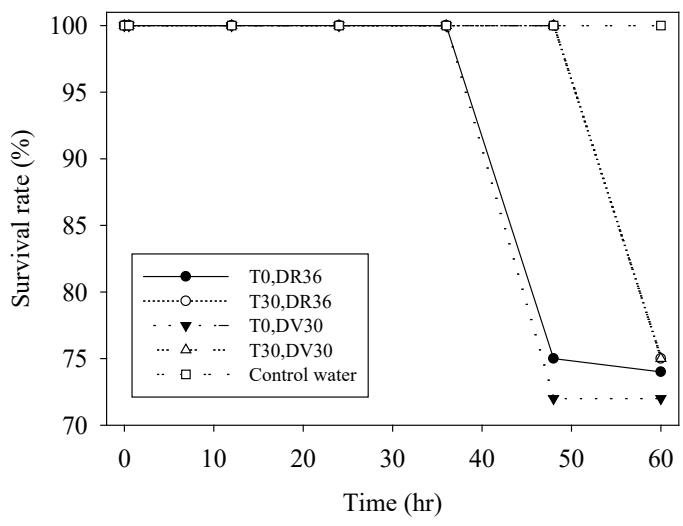

Fig. 5 Effects of different treated water and untreated water with survival rate (\%) of fairy shrimp (T0 is original dye at $300 \mathrm{ppm}, \mathrm{T} 30$ is treated water, and control water is water from a freshwater fairy shrimp 
culture.

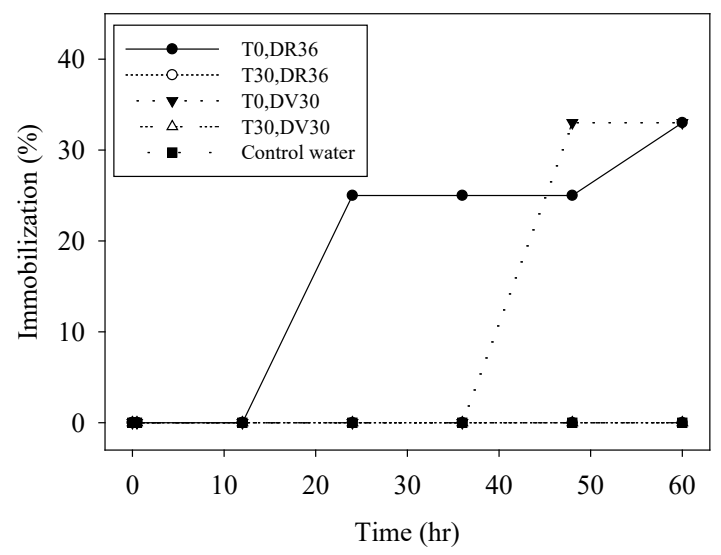

Fig. 6. Effects of different treated water and untreated water with immobilization (\%) of fairy shrimp, T0 is original dye at $300 \mathrm{ppm}, \mathrm{T} 30$ is treated water, and control water is water from a freshwater fairy shrimp culture

The immobilization test of the fairy shrimps was also carried out and presented in Fig.6. The test mainly involved observing the movement of the laboratory animals. The experiment result revealed no abnormal movement of the fairy shrimps in the control water and all the treated water. However, only in the untreated water (DR36), 25\% of immobilization was observed at $24 \mathrm{~h}$, while in the untreated water (DV30), 33\% of immobilization was observed at $48 \mathrm{~h}$. This result indicated the treated water was less harmful to the fairy shrimps than the untreated water.

\section{Conclusion}

A Box-Behnken design was used to find the optimal condition for dye decolorizing efficiency by considering the three variables, including initial $\mathrm{pH}$, catalyst dosage and initial concentration of hydrogen peroxide. The initial $\mathrm{pH}$ was found to be the most influential parameter on dye decolorization efficiency. The Least Square of Error method was used to create the models for predicting the dye decolorizing efficiency for DR36 and DV30, respectively. The model can be used to predict the optimal decolorization conditions for DR36 and DV30. The optimal conditions were experimentally verified, and it was found that the predicted DE\% was in good agreement with the experimental values. More importantly, the treated water was in compliance with the American Dye Manufacturing Institute and Thailand's 
421 Industrial Wastewater Discharge standards. The toxicity test revealed no acute toxicity. Therefore, the Fenton-like

422 reaction using iron-powder as the catalyst is suitable for removing DR36 and DV30.

423

424

425

426

427

428

429

430

431

432

433

434

435

436

437

438

439

440

441

442

443

444

445

446

447

448

449

450

451

452

453

454

455

456

457

\section{Acknowledgements}

This research was granted by Research Fund of the Faculty of Engineering, Khon Kaen University, Thailand, contract No. 4-1/2559.

-Ethical Approval: Compliance with Ethical Standards

-Consent to Participate: All applicable international, national, and/or institutional guidelines for the care and use of animals were followed.

-Consent to Publish: Not applicable

-Authors' Contributions: Natwat Srikhao planed, designed the experiments, collected data, interpreted, analyzed, and wrote a manuscript. Arthit Neramittagapong, Pongsert Sriprom, and Sutasinee Neramittagapong designed the experiments, provided chemicals and instruments, interpreted, analyzed, discussed, and wrote a manuscript. Somnuk Theerakulpisut and Nurak Grisdanurak interpreted, analyzed, discussed, and wrote a manuscript

-Funding: This study was funded by the Research Fund of the Faculty of Engineering, Khon Kaen University, Thailand, contract No. 4-1/2559.

-Competing Interests: The authors declare that they have no competing interests.

-Availability of data and materials: Not applicable

\section{Reference}

Ay F, Catalkaya EC, Kargi F (2009) A statistical experiment design approach for advanced oxidation of Direct Red azo-dye by photo-Fenton treatment. J Hazard Mater 162:230-236. https://doi.org/10.1016/j.jhazmat.2008.05.027

Ayyob M, Ahmad I, Hussain F, Kashif Bangash M, Awan JA, Jaubert JN (2020) A new technique for the synthesis of lanthanum substituted nickel cobaltite nanocomposites for the photo catalytic degradation of organic dyes in wastewater. Arab J Chem 12:6341-6347. https://doi.org/10.1016/j.arabjc.2020.05.036

Berkani M, Kadmi Y, Bouchareb MK, Bouhelassa M, Bouzaza A (2020) Combination of a Box-Behnken design technique with response surface methodology for optimization of the photocatalytic mineralization of C.I. Basic Red 46 dye from aqueous solution. Arab J Chem https://doi.org/10.1016/j.arabjc.2020.05.013 
458

459

460

461

462

463

464

465

466

467

468

469

470

471

472

473

474

475

476

477

478

479

480

481

482

483

484

485

486

487

488

489

490

491

492

493

494

Bouzayani B, Meijide J, Pazos M, Elaoud SC, Sanroman MA (2017) Removal of polyvinylamine sulfonate anthrapyridone dye by application of heterogeneous electro-Fenton process. Environ Sci Pollut Res 24:1830918319. https://doi.org/10.1007/s11356-017-9468-5

Chu L, Wang J, Dong J, Liu H, Sun X (2012) Treatment of coking wastewater by an advanced Fenton oxidation process using iron powder and hydrogen peroxide. Chemosphere 86:409-414. https://doi.org/10.1016/j.chemosphere.2011.09.007

Dias FF, Oliveira AAS, Arcanjo AP, Moura FCC, Pacheco JGA (2016) Residue-based iron catalyst for the degradation of textile dye via heterogeneous photo-Fenton. Appl Catal B Environ 186:136-142. https://doi.org/10.1016/j.apcatb.2015.12.049

Ertugay N, Acar FN (2017) Removal of COD and color from Direct Blue 71 azo dye wastewater by Fenton's oxidation: Kinetic study. Arab J Chem 10:S1158-S1163. https://doi.org/10.1016/j.arabjc.2013.02.009

Fernandes NC, Brito LB, Costa GG, Taveira SF, Cunha-Filho MSS, Oliveira GAR, Marreto RN (2018) Removal of azo dye using Fenton and Fenton-like processes: Evaluation of process factors by Box-Behnken design and ecotoxicity tests. Chem Biol Interact 291:47-54. https://doi.org/10.1016/j.cbi.2018.06.003

Fida H, Zhang G, Guo, Naeem A (2017) Heterogeneous Fenton degradation of organic dyes in batch and fixed bed using La-Fe montmorillonite as catalyst. J Colloid Interface Sci 490:859-868. https://doi.org/10.1016/j.jcis.2016.11.085

Fu JF, Zhao YQ, Xue XD, Li WC, Babatunde AO (2009) Multivariate-parameter optimization of acid blue-7 wastewater treatment by Ti/TiO2 photoelectrocatalysis via the Box-Behnken design. Desalination 243:42-51. https://doi.org/10.1016/j.desal.2008.03.038

Ghanbari F, Moradi M, Manshouri M (2014) Textile wastewater decolorization by zero valent iron activated peroxymonosulfate: Compared with zero valent copper. J Environ Chem Eng 2:1846-1851. https://doi.org/10.1016/j.jece.2014.08.003

Glugoski LP, Cubas PDJ, Fujiwara ST (2017) Reactive Black 5 dye degradation using filters of smuggled cigarette modified with Fe3 ${ }^{+}$. Environ Sci Pollut Res 24:6143-6150. https://doi.org/10.1007/s11356-016-6820-0

Grisales CM, Salazar LM, Garcia DP (2019) Treatment of synthetic dye baths by Fenton processes: evaluation of their environmental footprint through life cycle assessment. Environ Sci Pollut Res 26:4300-4311. https://doi.org/10.1007/s11356-018-2757-9

Holkar CR, Jadhav AJ, Pinjari DV, Mahamuni NM, Pandit AB (2016) A critical review on textile wastewater treatments: Possible approaches. J Environ Manage 182:351-366. https://doi.org/10.1016/j.jenvman.2016.07.090

Khataee A, Gholami P, Sheydaei M (2016) Heterogeneous Fenton process by natural pyrite for removal of a textile dye from water: Effect of parameters and intermediate identification. J Taiwan Inst Chem Eng 58:366-373. https://doi.org/10.1016/j.jtice.2015.06.015

Khataee A, Salahpour F, Fathinia M, Seyyedi B, Vahid B (2015) Iron rich laterite soil with mesoporous structure for heterogeneous Fenton-like degradation of an azo dye under visible light. J Ind Eng Chem 26:129-135. 
https://doi.org/10.1016/j.jiec.2014.11.024

Li K, Zhao Y, Janik MJ, Song C, Guo X (2017) Facile preparation of magnetic mesoporous Fe3O4/C/Cu composites as high performance Fenton-like catalysts. Appl Surf Sci 396:1383-1392. https://doi.org/10.1016/j.apsusc.2016.11.170

Lyu C, Zhou D, Wang J (2016) Removal of multi-dye wastewater by the novel integrated adsorption and Fenton oxidation process in a fluidized bed reactor. Environ Sci Pollut Res 23:20893-20903. https://doi.org/10.1007/s11356-016-7272-2

Ma J, Zhou L, Dan W, Zhang H, Shao Y, Bao C, Jing L (2015) Novel magnetic porous carbon spheres derived from chelating resin as a heterogeneous Fenton catalyst for the removal of methylene blue from aqueous solution. $\mathrm{J}$ Colloid Interface Sci 446:298-306. https://doi.org/10.1016/j.jcis.2015.01.036

Malade LV, Deshannavar UB (2018) Decolorisation of Reactive Red 120 by hydrodynamic cavitation. Mater Today Proc 5:18400-18409. https://doi.org/10.1016/j.matpr.2018.06.180

Nallathambi A, Venkateshwarapuram Rengaswami GD (2017) Industrial scale salt-free reactive dyeing of cationized cotton fabric with different reactive dye chemistry. Carbohydr Polym 174:137-145. https://doi.org/10.1016/j.carbpol.2017.06.045

Nasuha N, Ismail S, Hameed BH (2016) Activated electric arc furnace slag as an efficient and reusable heterogeneous Fenton-like catalyst for the degradation of Reactive Black 5. J Taiwan Inst Chem Eng 67:235243. https://doi.org/10.1016/j.jtice.2016.07.023

Nidheesh PV, Zhou M, Oturan MA (2018) An overview on the removal of synthetic dyes from water by electrochemical advanced oxidation processes. Chemosphere 197:210-227. https://doi.org/10.1016/j.chemosphere.2017.12.195

OCDE Guideline for Testing of Chemical (1984) Dapnhia sp Acute Immobilisation Test and Reproduction Test. Guideline:1-16.

Powar AS, Perwuelz A, Behary N, Hoang L, Aussenac T (2020) Application of ozone treatment for the decolorization of the reactive-dyed fabrics in a pilot-scale process-optimization through response surface methodology. Sustain 12. https://doi.org/10.3390/su12020471

Punzi M, Anbalagan A, Aragão BR, Svensson BM, Jonstrup M, Mattiasson B (2015) Degradation of a textile azo dye using biological treatment followed by photo-Fenton oxidation: Evaluation of toxicity and microbial community structure. Chem Eng J 270:290-299. https://doi.org/10.1016/j.cej.2015.02.042

Quadrado RFN, Fajardo AR (2017) Fast decolorization of azo methyl orange via heterogeneous Fenton and Fentonlike reactions using alginate-Fe2+/Fe3+ films as catalysts. Carbohydr Polym 177:443-450. https://doi.org/10.1016/j.carbpol.2017.08.083

Rache ML, García AR, Zea HR, Silva AMT, Madeira LM, Ramírez JH (2014) Azo-dye orange II degradation by the heterogeneous Fenton-like process using a zeolite Y-Fe catalyst-Kinetics with a model based on the Fermi's equation. Appl Catal B Environ 146:192-200. https://doi.org/10.1016/J.APCATB.2013.04.028

Sohrabi MR, Khavaran A, Shariati S, Shariati S (2017) Removal of Carmoisine edible dye by Fenton and photo Fenton processes using Taguchi orthogonal array design. Arab J Chem 10:S3523-S3531. 
https://doi.org/10.1016/j.arabjc.2014.02.019

Sohrabi MR, Moghri M, Fard Masoumi HR, Amiri S, Moosavi N (2016) Optimization of Reactive Blue 21 removal by Nanoscale Zero-Valent Iron using response surface methodology. Arab J Chem 9:518-525. https://doi.org/10.1016/j.arabjc.2014.11.060

Vilardi G, Di Palma L, Verdone N (2018) On the critical use of zero valent iron nanoparticles and Fenton processes for the treatment of tannery wastewater. J Water Process Eng 22:109-122. https://doi.org/10.1016/J.JWPE.2018.01.011

Wang J, Liu C, Li J, Luo R, Hu X, Sun X, Shen J, Han W, Wang L (2017) In-situ incorporation of iron-copper bimetallic particles in electrospun carbon nanofibers as an efficient Fenton catalyst. Appl Catal B Environ 207:316-325. https://doi.org/10.1016/j.apcatb.2017.02.032

Youssef NA, Shaban SA, Ibrahim FA, Mahmoud AS (2016) Degradation of methyl orange using Fenton catalytic reaction. Egypt J Pet 25:317-321. https://doi.org/10.1016/j.ejpe.2015.07.017 
Figures
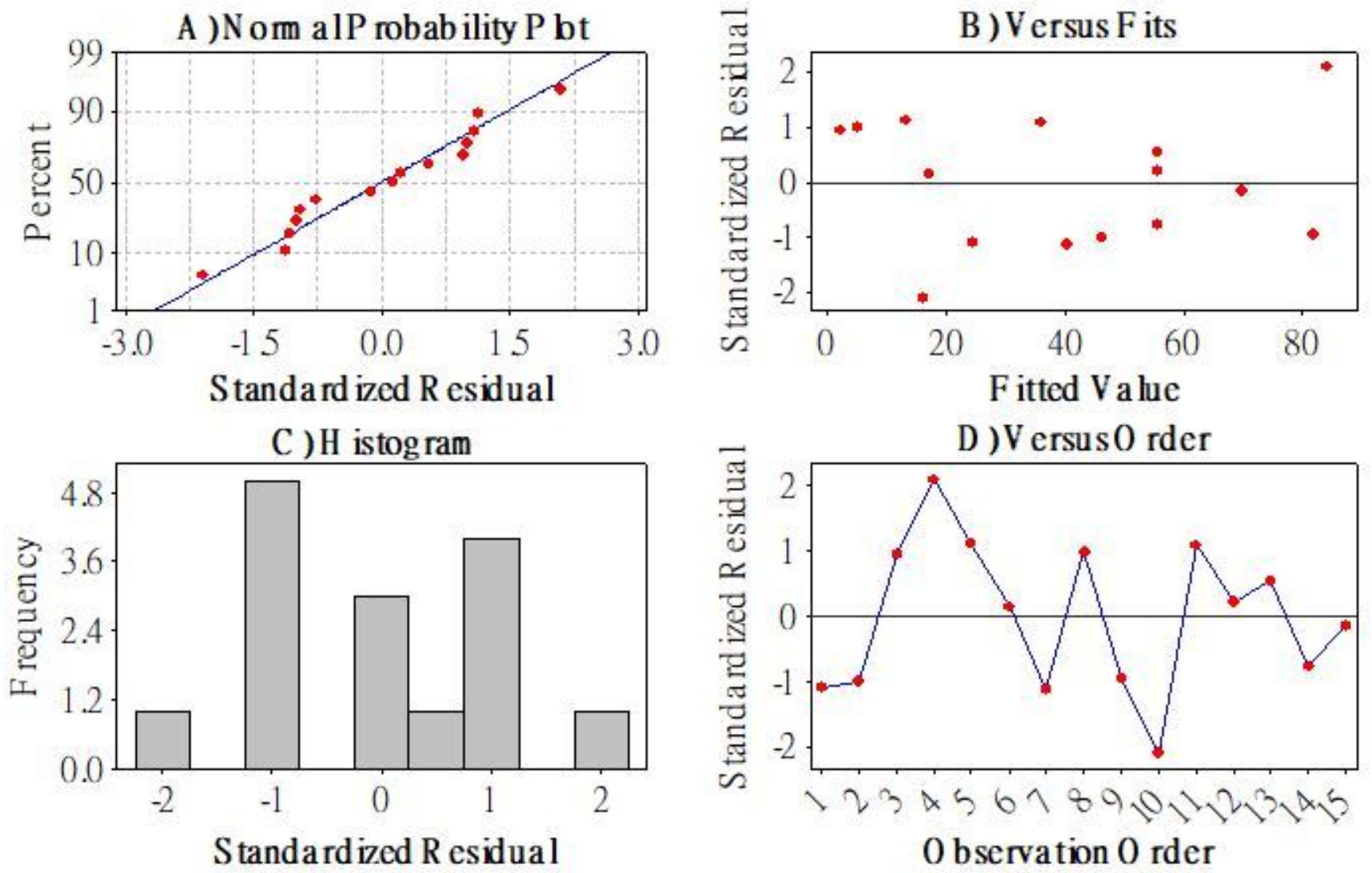

Figure 1

Standard error compared to a) standardized residual b) versus fits c) Histogram d)Versus order. 

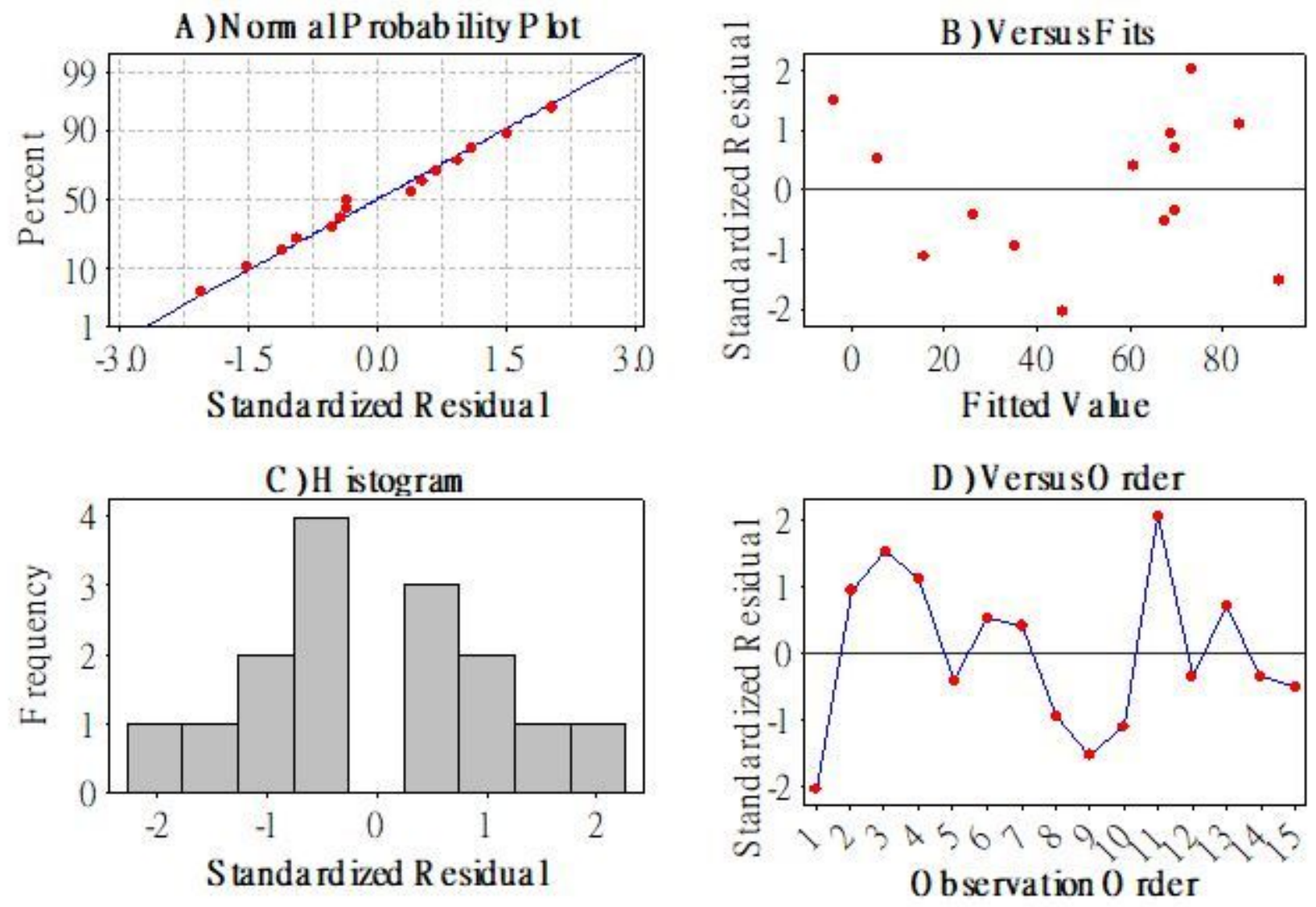

Figure 2

Standard error compared to A) standardized residual B) versus fits C) Histogram D) Versus Order. For DV30.
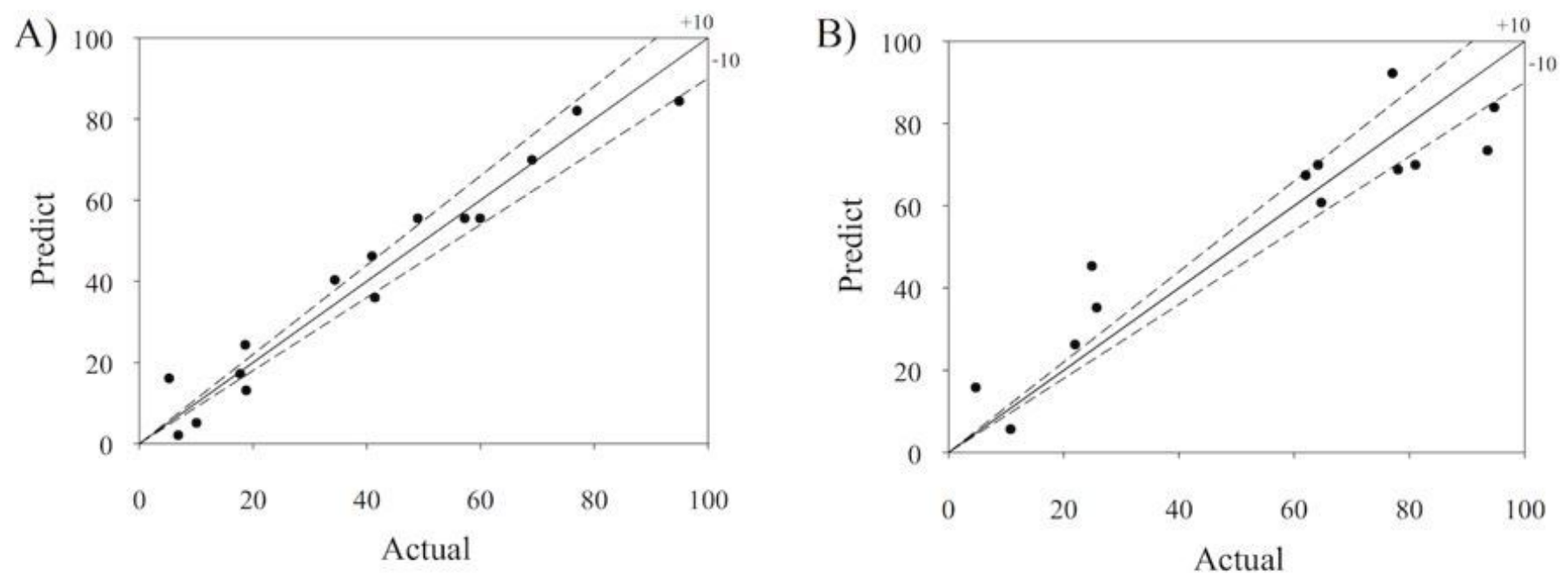

Figure 3 
Experimental and predicted equation results for decolorization A) DR36 B) DV30
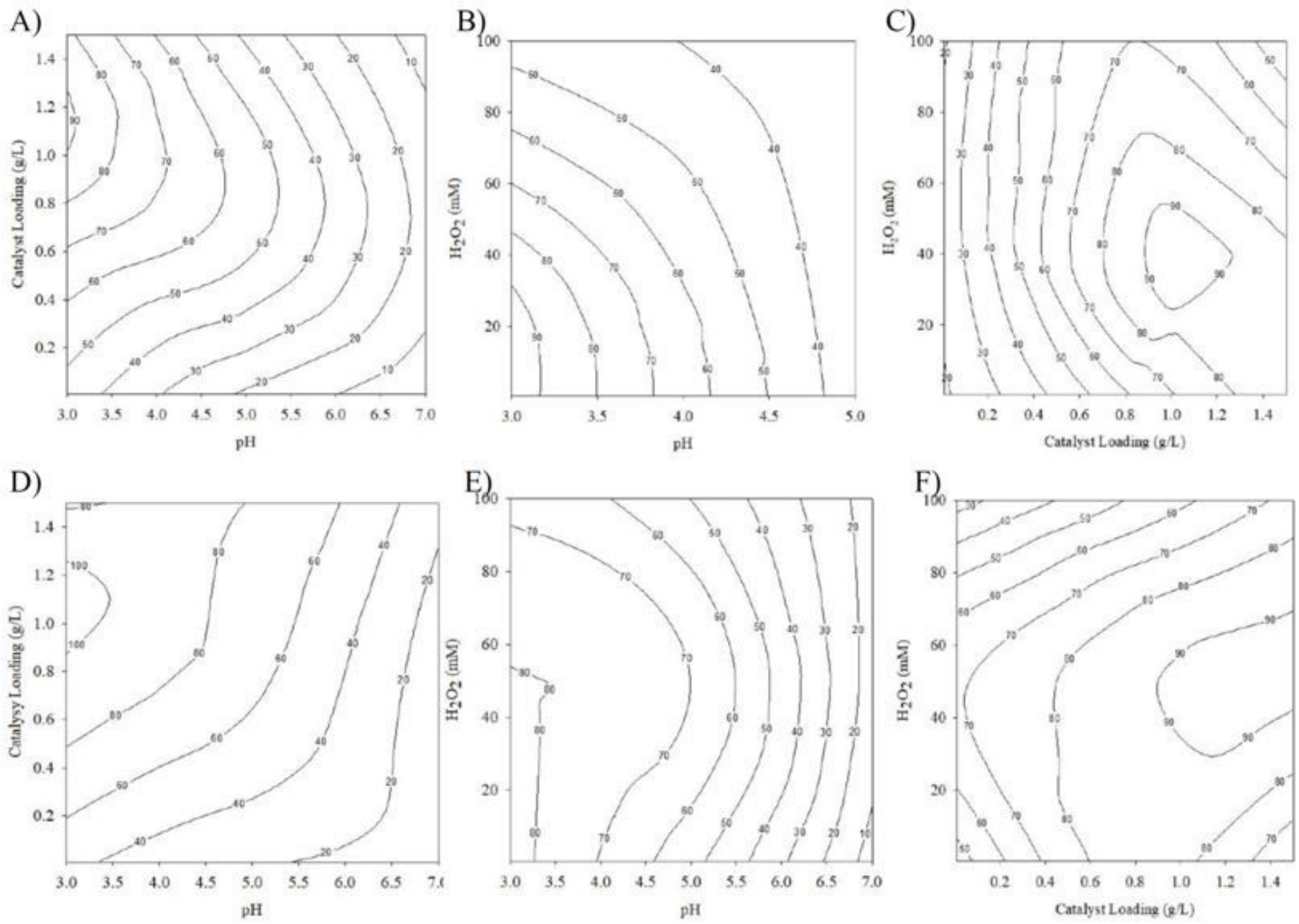

\section{Figure 4}

Contour plot illustrations, the interaction effect of variables on dye decolorization efficiency in the Fenton -like process in white (A-C) For DR36 and (D-F) for DV30. 


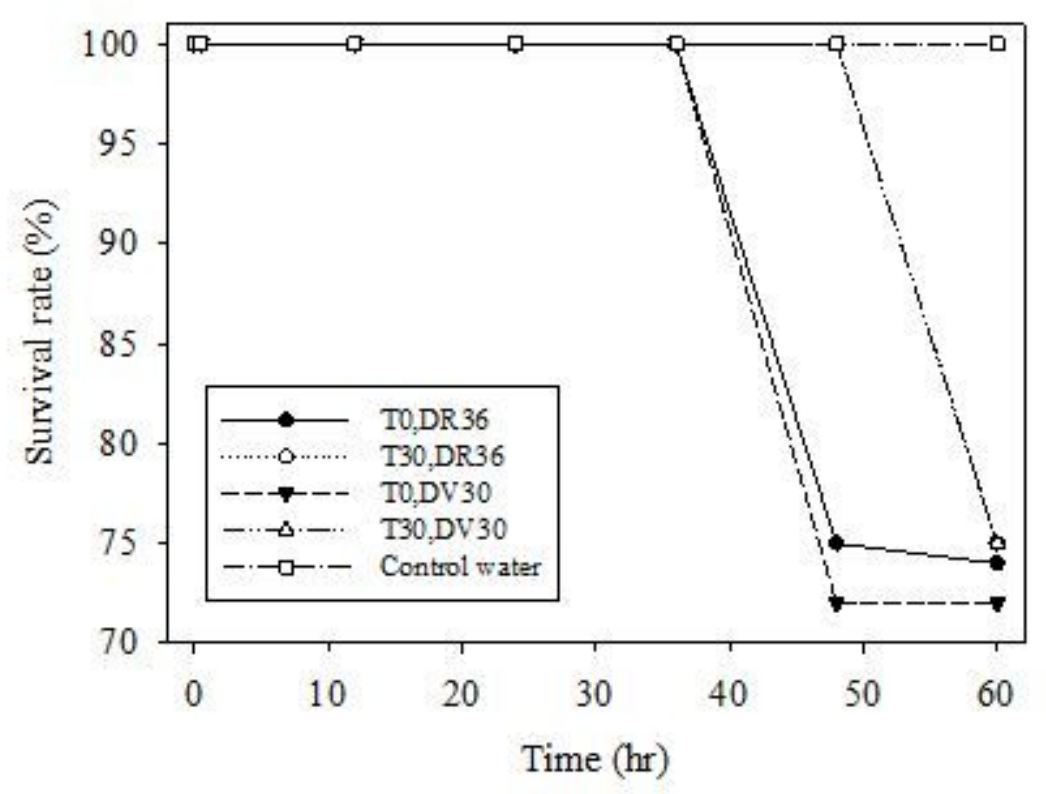

\section{Figure 5}

Effects of different treated water and untreated water with survival rate (\%) of fairy shrimp (T0 is original dye at 300 ppm, T30 is treated water, and control water is water from a freshwater fairy shrimp

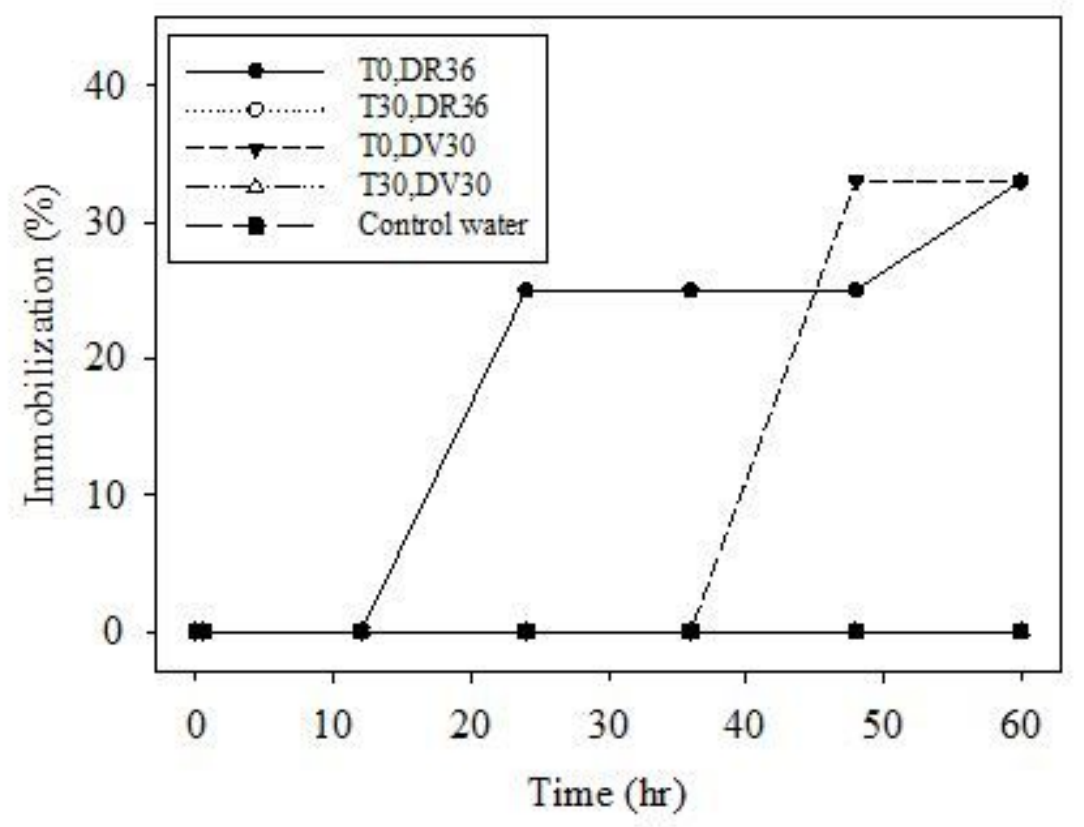

Figure 6

Effects of different treated water and untreated water with immobilization (\%) of fairy shrimp, T0 is original dye at 300 ppm, T30 is treated water, and control water is water from a freshwater fairy shrimp culture 